\title{
Simulation of root water uptake under combined soil moisture and salinity stress
}

\author{
Li yuqing, Zhangcun, Zhang Wenxian \\ XiZang Agriculture and Animal Husbandry College, Linzhi , XiZang, 86000

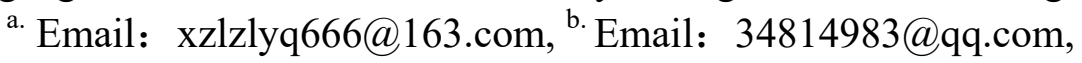 \\ c.Email: 437995021@qq.com
}

Keywords: Water uptake, Salinity and water stress, Reduction function, SWMS 2D, Numerical simulation

\begin{abstract}
The objective of this study was to develop a mathematical model that describes soil water movement and root water uptake under the conditions of combined stress of soil moisture and salinity. The mass transport equations of salts have been incorporated as part of the integrated model SWMS_2D and the soil salinity was represented by the soil electrical conductivity. There was good agreement between the simulated and measured values of the water content and salinity. The modified version of model SWMS 2D is able to predict the water uptake process under the combined stress of soil moisture and salinity and it is suitable for irrigation management in areas with scarce and low quality water resources.
\end{abstract}

\section{Introduction}

Actual root water uptake not only depends on the root distribution and its functioning, but also on soil water availability and salinity. In addition to water stress in periods of low water availability, root water uptake is also reduced when concentrations of soluble salts exceed plant-specific threshold values (Zipper et al., 2015). In irrigated soils, particularly in arid and semiarid regions, plants are generally subjected to both salinity and water stress. In these regions, soil and water management practices are based on maintaining a favorable soil water content and salinity status in the root zone, thereby minimizing periods of water stress while controlling leaching to minimize salinity stress.

There are two different approaches to quantify soil water extraction rate, namely the microscopic and the macroscopic approaches. The microscopic approach (Molz and Peterson, 1976; Mandri and Ronald, 1997; Askri et al., 2010) considered that radial flow towards a representative individual root can be represented by an infinitely long cylinder of uniform radius and water absorbing properties. This approach described radial flow to a single root from a cylinder of soil surrounding the root with boundary conditions at the root surface (inner side of the soil cylinder) 
and the outer side of the soil cylinder. Whereas, this type of model is not practical because it is difficult to measure the detailed geometry of a growing root system and the water permeability of root varies with position along the root (Wu et al., 2015). The macroscopic approach (Feddes et al., 1978, Homaee, et al., 2002; Kargas, et al., 2012) deals with the removal of water from the root zone as a whole. The flow to individual roots is ignored and the overall root system is assumed to extract water from each point of the root zone. While the complete insight into the physical process of root water uptake was not required and therefore the determination of soil and plant parameters were more empirical (Feddes, 1988; Zhuang et al., 2001, Lekakis et al., 2011; Rasouli et al., 2013).

In view of these shortcomings, we induce a new reduction function for the combined water and salinity stress. The impact of salt built up and salinity on plant root water uptake was also evaluated.

\section{Material and Methods}

The Richard's equations is frequently considered to govern water flow in partially saturated soils. In a one-dimensional vertical system, this equation is given by:

$$
C(h) \frac{\partial h}{\partial t}=\frac{\partial}{\partial z}\left[K(h) \frac{\partial h}{\partial z}-1\right]-S_{r}
$$

where $h$ is the soil water head, $C$ is the soil water capacity which is equal to the slope $(d \theta / d h)$ of the water retention curve, $t$ is the time; $z$ is the depth (positive downward from the soil surface), $K$ is the hydraulic conductivity and $S_{r}$ is the soil water extraction rate by plant root. The root extraction term reads:

$$
S_{r}=\alpha(\theta, C) S_{r \max }
$$

in which $\theta$ is the soil water content, $S_{r \max }$ is the maximum rate and $\alpha(\theta, C)$ is the reduction function depending on soil water content and solute concentration. It is assumes that the extraction term under non-stress conditions is equal to potential transpiration. Crop water storage is assumed negligible. A model for water-uptake under combined stress of salinity and soil moisture can be expressed as

$$
\begin{aligned}
& \alpha=\frac{1-e^{-r_{1} X_{1}}}{B-e^{-r_{1} X_{1}} \cdot e^{-r_{2} X_{2}}} \\
& B=e^{r_{3} X_{2}+r_{4}\left(1-X_{1}\right)}
\end{aligned}
$$

in which $\alpha=T_{a} / T_{p}, T_{a}$ and $T_{p}$ are the actual and potential transpiration, respectively. the soil water stress factor, $X_{1}$ is the function of effective moisture content

$$
X_{1}=\frac{\theta-\theta_{0}}{\theta_{f}-\theta_{0}}
$$


Where, $\theta$ is the soil water content, $\theta_{0}$ is the lower limit soil water content(wilting point), $\theta_{f}$ is the threshold value of soil water content under which the transpiration decrease from the maximum value. For $\theta \leq \theta_{0}$, water stress factor $X_{1}$ is zero; for $\theta \geq \theta_{f}$, water stress factor is assume to be the maximum value of 1.0 .

The salinity stress factor $X_{2}$ is the function of soil electrical conductivity

$$
X_{2}=E C-E C_{c}
$$

When no water stress and salinity stress occurs, $X_{1}$ and $X_{2}$ are equal to 1 and 0 respectively, Then the equation 3 yields:

$$
\alpha=\frac{1-e^{-r_{1}}}{e^{0}-e^{-r_{1}} e^{0}}=\frac{1-e^{-r_{1}}}{1-e^{-r_{1}}}=1
$$

For condition where $\theta \leq \theta_{0}, X_{1}$ is equal to 0 . Equation 3 yields:

$$
\alpha=\frac{1-e^{0}}{B-e^{0} \cdot e^{-r_{2} X_{2}}}=0
$$

When water stress occurs without salinity stress, $X_{2}$ is equal to 0 . Equation 3 yields:

$$
\alpha=\frac{1-e^{-r_{1} X_{1}}}{e^{r_{4}\left(1-X_{1}\right)}-e^{-r_{1} X_{1}}}
$$

where $E C$ and $E C_{c}$ are the electrical conductivity of soil solution and the threshold electrical conductivity under which no salinity stress occurs. $r_{1}, r_{2}, r_{3}$ and $r_{4}$ are soil, crop and phenomenological stage-specific parameters.

\section{Results and Discussion}

A graphical representation of the soil column and the finite element mesh used for the numerical simulation is presented in Figure 1. The width and depth of the soil column is $15 \mathrm{~cm}$ and $20 \mathrm{~cm}$, respectively. The root distribution zone which describes the spatial variation of the potential extraction term (gray area) was also shown in Figure 1.

The initial soil moisture profile and solution concentration profile were equally distributed 
$h(x, z, t)=h_{0}(x, z)=-13.98$, for $t=0$

$c(x, z, t)=c_{0}(x, z)=2.0$, for $t=0$

where $h$ is the pressure head $\left(\mathrm{cmH}_{2} \mathrm{O}\right), c$ is the solution concentration $\left(\mathrm{g} / \mathrm{cm}^{3}\right)$.

Atmospheric boundary conditions were implemented in which time-dependent input data for the precipitation, potential evaporation and potential transpiration were specified in the input file ATMOSPH.IN. Other boundaries are specified as no flow boundary. Due to solute cannot leave the flow region across atmospheric boundaries, the upper boundary condition is specified as no flow boundary at the soil surface:

$$
\theta D_{i j} \frac{\partial c}{\partial x_{j}} n_{i}=0 \quad \text { for }(x, z) \in \Gamma_{n}
$$

where $\theta$ is the soil water content, $D_{i j}$ is the components of the dispersion coefficient tensor, $n_{i}$ is the components of the outward unit vector normal to boundary $\Gamma_{n}$.

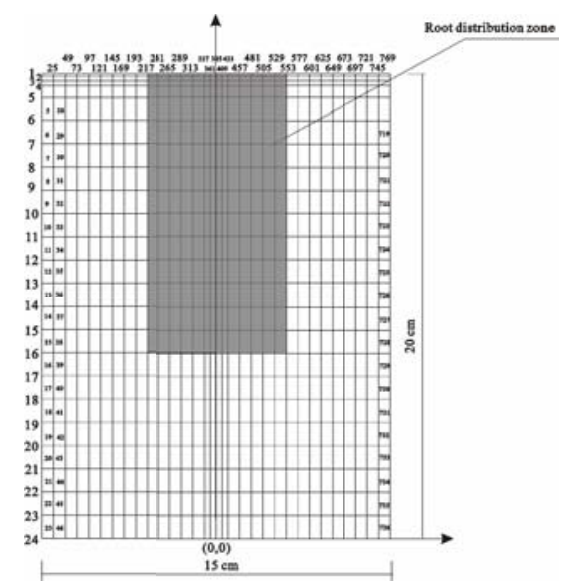

Fig.1 Flow system and finite element mesh

The parameters of the reduction model are estimated by fitting the function to the experimental data (Homaee et al., 2002). Values for the parameters in equations are given in table 1.

Table 1 Parameters used in the reduction model of Equation 2

\begin{tabular}{|c|c|c|c|c|}
\hline & $C_{1}$ & $C_{2}$ & $c_{3}$ & $C_{4}$ \\
\hline Value & 2.40 & 3.21 & 0.104 & 0.0285 \\
\hline
\end{tabular}

Figure 2 shows the possible shape of relative transpiration $\alpha$ as a function of water stress factor $X_{1}$ under non-salinity stress conditions. Figure 3 presents the possible shape of relative transpiration as a function of salinity stress factor $X_{2}$ under non-water stress conditions. 

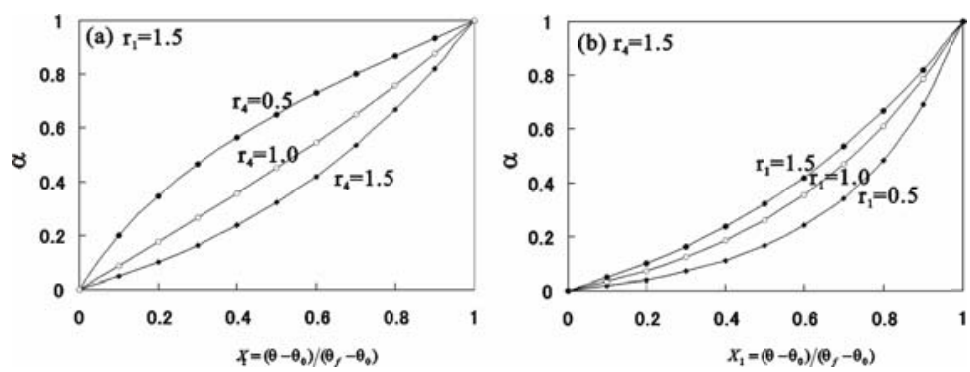

Fig.2. Relative transpiration $\alpha$ as a function of water stress factor $X_{1}$ under non-salinity stress conditions. (a) $r_{1}$ is set to 1.5 and $r_{4}$ is set to $0.5,1.0$ and 1.5 respectively; (b) $r_{4}$ is set to 1.5 and $r_{1}$ is set to $0.5,1.0$ and 1.5 respectively.
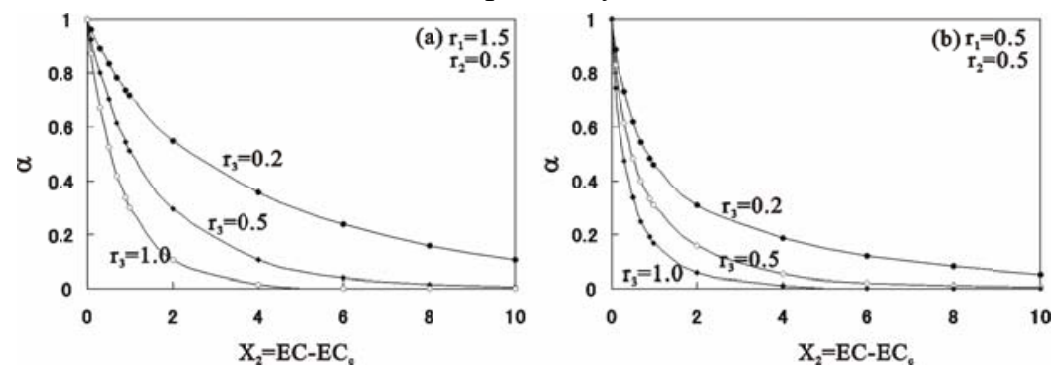

Fig.3. Possible shape of relative transpiration $\alpha$ as a function of salinity stress factor $X_{2}$ under non-water stress conditions.(a) $r_{1}, r_{2}$ is set to 1.5 and 0.5 , and $r_{3}$ is set to $0.2,0.5$ and 1.0 respectively; (b) $r_{1}, r_{2}$ is set to 0.5 and 0.5 , and $r_{3}$ is set to $0.2,0.5$ and 1.0 respectively.

Modeling of soil moisture movement and salt transport was done using the SWMS_2D model in which root water extraction term was modified according to Equation 4. In order to make a comparison, soil water movement and solute transport was also simulated with original SWMS_2D under the same assumed conditions. The simulation was carried out over a period of 20 days. Comparisons of soil moisture profile simulated with original SWMS_2D and modified SWMS_2D at $t=5,10$ and 20 days are presented in Figure 4. The solute concentration simulated with original SMWS_2D and modified SMWS_2D at $t=10$ and 20 days are presented in Figure 5.
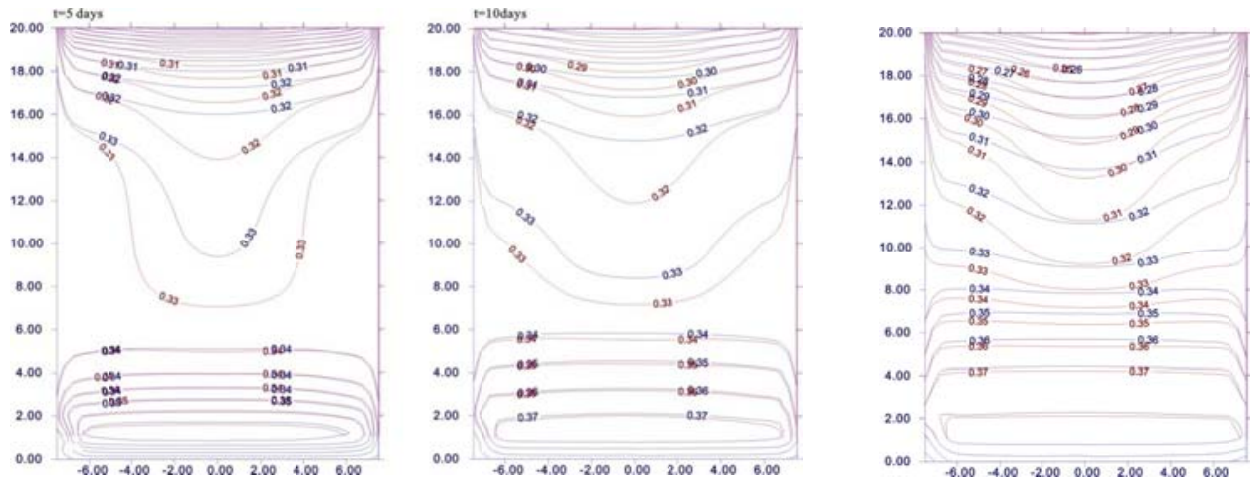

Fig.4 Comparisons of simulated soil moisture profile with original SWMS_2D and modified SWMS_2D at $t=5$, 10 and 20 days, respectively. 

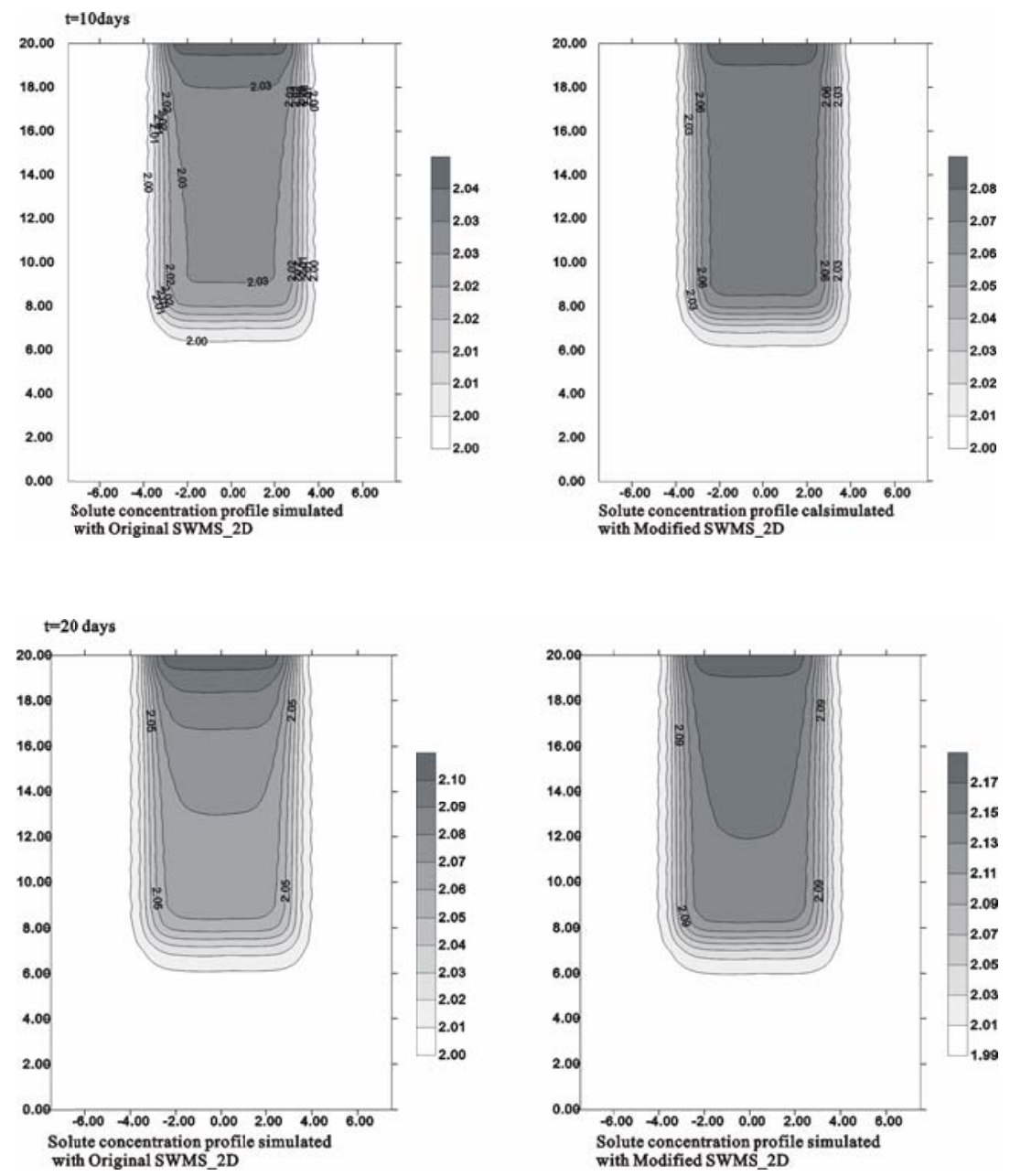

Fig.5 Comparisons of simulated profiles of solute concentrations with original SWMS_2D and modified SWMS_2D at $t=5,10$ and 20 days, respectively.

As presented in Figures 4 and 5, the responses of the crop water uptake to the salt stress were well described using the reduction function. Through observation of root and shoot growth and response to salinity, the varying degrees of salt stress were well determined.

\section{Conclusion}

A mathematical model that describes soil water movement and the root water uptake under the conditions of combined stress of soil moisture and salinity was developed. A reduction function was coupled into SWMS_2D to describe the response of crop water uptake to the combined stress of soil moisture and salinity.

The qualitative and quantitative procedures for results evaluation showed that there was good agreement between the simulated and measured values of the water content and salinity.

\section{Acknowledgements}

This work was partly supported by grants from the State's Key Project of Research and Development Plan of China (2016YFC0402405), and Chinese National Natural Science Foundation 
(Nos. 51379152, 51679257).

Key Special project of Science and Technology Department of Tibet(Z2016C01G01/07);Key projects of Science and Tech-nology Department of Tibet: Research and its prevention and control $\mathrm{t}$ echnology on agricultural non-point source pollution in Tibe

\section{References}

[1] Askri, B., Bouhlila, R., Job, J.O., 2010. Development and application of a conceptual hydrologic model to predict soil salinity within modern Tunisian oases. J.Hydrol. 380, 45-61.

[2] Dirksen C., Augustijn D.C. 1988. Root water uptake function for non-uniform pressure and osmotic potentials, Agric. Abstr., 18.

[3] Dirksen C., J.B.Kool, P. Koorevaar, van Genuchten, M.Th, 1993, HYSWASOR—simulation model of hysteretic water and solute transport in the root zone. In: Russo, D.,Dagan,G(Eds.), Water flow and solute transport in soils. Springer, New York, 99-122.

[4] Feddes, R.A. 1988. Modeling and simulation in hydrologic systems related to agriculture development: State of the art, Agric.Water Manage., 13, 235-248

[5] Homaee M., R.A.Feddes, C.Dirksen, 2002. A macroscopic water extraction model for nonuniform transient salinity and water stress, Soil Sci.Soc.Am.J., 66:1764-1772

[6] Kargas, G., Kerkides, P., Poulovassilis, A., 2012. Infiltration of rain water in semi-arid areas under three land surface treatments. Soil Tillage Res. 120, 15-24.

[7] Lekakis, E.H., Georgiou, P.E., Pavlatou-Ve, A., Antonopoulos, V.Z., 2011. Effects of fixed partial root-zone drying irrigation and soil texture on water and solute dynamics in calcareous soils and corn yield. Agric. Water Manage. 101, 71-80.

[8] Mandri O., M.A.Ronald, 1997. A model for water uptake in plants; Applied Mathematics and Computation, 84, 163-191

[9] Molz F.J., C.M.Peterson, 1976. Water transport from roots to soil, Agron.J., 68:901-904

[10] Rasouli, F., Pouya, A.K., Šimunek, J., 2013. Modeling the effects of saline water use in wheat-cultivated lands using the UNSATCHEM model. Irrig. Sci. 31, 1009-1024.

[11] Van Genuchten, M.Th, GJ.Hoffman, Analysis of crop salt tolerance data. In: Shainberg I Shalhevet J (eds) Soil salinity under irrigation: processes and management. Ecological studies on 51. Springer, Berlin Heidelberg New York, 1984:130-142.

[1] Wu, Y., Liu, T., Paredes, P., Duan, L., Pereira, L.S., 2015. Water use by a groundwater dependent maize in a semi-arid region of Inner Mongolia: evapotranspiration partitioning and capillary rise. Agric. Water Manage. $152,222-232$.

[1] Zipper, S.C., Soylu, M.E., Booth, E.G., Loheide, S.P., 2015. Untangling the effects of shallow groundwater and soil texture as drivers of subfield-scale yield variability. Water Resour. Res. 51 (8), 6338-6358.

[1] Zhuang J., Keiichi Nakayama. 2001. Estimation of root water uptake of maize, an ecophysiological perspective, Field crops research, 69:201-213 